\title{
Optimal Pricing of New Subscription Services: Analysis of a Market Experiment
}

\author{
Peter J. Danaher \\ Department of Marketing, University of Auckland, Private Bag 92019, Auckland, New Zealand \\ p.danaher@auckland.ac.nz
}

\begin{abstract}
There are now available a number of new subscription services that comprise a dual pricing system of a monthly access fee (rental) and a per-minute usage charge. Examples include cellular phones, the Internet, and pay TV. The usage and retention of such services depend on the absolute and relative prices of this dual system. For instance, a moderate access fee but a low-usage charge might initially appeal to customers, but later a low-usage customer might find the monthly fee unjustified and thereby relinquish the service. Providers of such services, therefore, usually offer several pricing packages to cater to differing customer needs.

The purpose of this study is to derive a revenue-maximizing strategy for subscription services, that is, the combination of access and usage price that maximizes revenue over a specified time period. An additional objective is to determine access and usage price elasticities because they have historically played an important role in theoretical pricing models. The application area is the cellular phone market, but for a new rather than an existing product. To help gauge the likely usage rates and customer retention, a field experiment is conducted in which several alternative price combinations are used. Specifically, a sample of potential residential customers (most of whom did not have an existing cell phone) were divided into four treatment groups. The first group were not charged an access fee but did have to pay a small per-minute usage charge. The second group also paid a small usage charge but in addition had three access price increases over the duration of the trial. The third group paid no access fee but had usage charge increases, while the fourth group had both access fee and usage charge increases. Usage levels for each respondent are recorded, as is their month of dropout if they discontinue the service.

An initial examination of the data shows that higher access fees result in higher customer attrition, and higher usage cost results in lower usage. Furthermore, usage and retention are related in that declining usage levels over time often signal impending customer attrition. Hence, two phenomena need to be modeled: usage of the service and customer retention conditional on usage. Some seasonal effects are also observed and are allowed for in the model. Mod-
\end{abstract}

eling customer attrition simultaneously with usage is important because ignoring customer attrition will likely result in an underestimate of price sensitivity. This results from a censoring effect, whereby respondents who remain in the trial tend to be wealthier, and hence, less price sensitive.

Given the known problems of ignoring customer attrition, we develop a theoretical model of usage, which explicitly incorporates attrition by extending a time-series model introduced by Hausman and Wise (1979). We make two extensions of the Hausman and Wise model. The first is to generalize it from two to many time periods and the second is to allow for respondent heterogeneity by incorporating latent classes. We fit the model by maximum likelihood and find that a two-segment model is best. In addition, we examine the predictive validity of our model and find it to be reasonably good.

In general, the results show that access and usage prices have different relative effects on demand and retention. There are five key results. First, access price has some effect on usage but a much stronger effect on retention. Second, usage price has a strong effect on usage and a moderate effect on retention, in that if usage price increases so much that usage declines, then lower usage levels results in higher attrition. Third, access price elasticity is about half that of usage price, with both elasticities generally being much smaller than 1, indicating relative inelasticity for this particular service. Fourth, customer attrition rate (churn) is much more sensitive to access than usage price and, last, if just observed usage is examined and customer attrition is ignored, then price sensitivity is very likely to be substantially underestimated (on the order of $45 \%$ in our case).

Finally, when developing the revenue-maximizing price combination we allow for the cost of customer acquisition by using some typical advertising-to-sales ratios for the telecommunications industry. We find that the revenue maximizing price is $\$ 27.70$ per month for the access fee and $\$ 0.81$ per minute for the airtime charge. These values are in line with current access fees and usage costs in the given market. (Attrition; Field Experiment; Pricing; Price Elasticity; Subscription; Telecommunications) 


\section{Introduction}

In recent years three new subscription-based services have made rapid adoption, namely, cellular phones, the Internet, and pay TV. All these services are characterized by a dual pricing system, comprising a monthly access fee (rental) and a usage charge. ${ }^{1}$ Mahajan et al. (1982) comment that the price package for new subscription services has a major impact on their adoption and retention. For instance, a customer with only a moderate interest in the Internet might subscribe to an ISP on the basis of low per-minute usage rates but later discontinue subscription because their low-usage levels do not justify the expense of a high monthly access fee (Lemon and Winer 1995).

As information technology advances, the opportunity for more subscription-based services will increase. For example, traditional print media in an online setting could charge a monthly subscription fee and a usage charge on the basis of the number of pages browsed, or even charge for advertising viewed. In this environment, there is increasing need for marketers to understand consumer price sensitivity to new and existing subscription services. Pricing has been one of the cornerstone subjects in marketing, and much work has been done on price elasticities, the impact of competition, and profit maximization (see Gijsbrechts 1993, Oren 1984, Rao 1984, Winer 1986). Many of the pricing principles have been developed in the economics literature, but Ratza (1993, p. 55) notes in the services arena that "although economic principles do provide pricing guidelines, they are often too general to apply to everyday business settings." For instance, for new services, it is not recommended that price be set on the basis of covering fixed costs and instead should be determined by acceptance in the marketplace (Gabor 1988).

If marketplace pricing is recommended, then clearly there are going to be difficulties when setting the price for a new (unseen and untried) service compared with an existing service. One technique previously developed, especially for telecommunications,

${ }^{1}$ Pay TV does not usually have a usage charge, except for some movies and special sporting events like the Olympics and boxing, but the introduction of interactive digital TV will see an increase in consumption of pay-per-view. is theoretical price modeling, which aims at achieving market efficiency, an example being Ramsey pricing (Brown and Norgaard 1992, Mitchell and Vogelsang 1990). Other methods include surveys of purchase intentions (Puliyel and Ravi 1990), highest and lowest expected price (Gabor and Granger 1968), conjoint analysis (Dolan and Simon 1996, Kohli and Mahajan 1991, Mahajan et al. 1982, Wittink and Cattin 1989), and market tests (Ehrenberg and England 1990, Mohn 1995, Herriges and King 1994). All of these methods have their weaknesses, in particular a lack of marketplace validity (especially for purchase intention surveys; see Morwitz et al. 1993). One of the better methods, but also one of the most expensive, is a marketplace experiment. Here, alternative pricing scenarios are given to different groups of potential customers, and their usage and retention of the product is monitored over time.

In this paper, we examine a market experiment in which a panel of homes were recruited to trial a new telecommunications product. ${ }^{2}$ Both access and usage price were manipulated, but at different levels for subgroups of the panel. The analysis of the experiment is complicated by the occurrence of panelist attrition throughout the yearlong trial. The purpose of this study is to derive a revenue-maximizing strategy, that is, the combination of access and usage price that maximizes revenue over a specified time period. An additional objective is to determine access and usage price elasticities because they have historically played an important role in theoretical pricing models developed in the economics literature.

The paper proceeds as follows. In the next section, we give an overview of the experiment. Following this, we develop a model for the observed usage data, which incorporates attrition of panelists from the experiment. The fourth section applies the model to the experimental data, while the fifth section examines model fit. In the sixth section, we derive access and

${ }^{2}$ Conjoint analysis has also been used successfully in the past for two-part tariffing (Dolan and Simon 1996). However, in our case, using a cellular phone-type product, there is wide variation in use across time, and consumers are generally not good at predicting their usage levels, making conjoint analysis less attractive than a marketplace experiment. 
usage price elasticities. The last section estimates total revenue from the model, and this is used to determine the optimal pricing strategy. We conclude by looking at other potential applications for our model and its limitations.

\section{Overview of the Market Experiment}

To help motivate the relevant modeling and managerial issues, we now give an overview of the market experiment analyzed in this article, which is for a new subscription service in the telecommunications industry. For proprietary reasons, we cannot say what the service is, although it is similar to a cellular telephone service.

In this experimental trial, a sample of potential residential customers (most of whom did not have an existing cell phone) were divided into four treatment groups. The first group were not charged an access fee but did have to pay a small per-minute usage charge. The second group also paid a small usage charge but in addition had three access price increases over the duration of the trial. The third group paid no access fee but had usage charge increases, while the fourth group had both access fee and usage charge increases. Full details of the price levels and sample are given later.

Prices were increased rather than decreased over time because one of the purposes of the experiment was to find the price level at which customers relinquish the service, either because the fixed monthly charge was too high or because their usage declined so much that the monthly fixed charge exceeded their utility for the service. Customer attrition is a major problem in the cellular phone industry (Bolton 1998), so understanding the effect of price on retention is important in this application. If prices had started high and declined, there might have been a danger of biasing the recruited panel to higher income people. Furthermore, if prices had declined for these wealthier panelists, they would be less inclined to relinquish the service. As a result, price elasticity would likely be underestimated.
Figure 1 gives a graphical display of the data, showing two key measures. The first is the average usage level (indexed against each person's first month of usage), while the second is the proportion of the original customers that remain in the trial, which is indicated by the width of the bars. Each bar width is indexed against the width of the first month's bar (see Sheiner et al. 1997 for a similar graph showing results from clinical trials). The price changes are illustrated by a change in the shading of the bars, occurring every three months, in November, February, and May. An examination of Figure 1 reveals three key observations:

(i) Even though price Plan A has no access fee and very low usage rates, there is still some customer attrition. There is also a drop in usage levels in the summer months of July and August, followed by a return to normal in October, indicating a seasonal effect for usage.

(ii) Plans B and D, with increasing access fees, have the highest trialist rate of attrition, $41 \%$ and $46 \%$, respectively, over the entire duration of the experiment. Because Plan C's attrition rate is about the same as A's (both about 25\%), it is apparent that the biggest driver of customer attrition is the access fee, rather than the usage charge.

(iii) Usage for Plans C and D drops markedly after the third price increase and does not recover at the end of summer, as happens for plan A. Therefore, Plans $C$ and D are most similar with respect to usage (and not attrition), leading to the conclusion that usage is affected more by the per-minute usage charge rather than the monthly access fee.

Regarding point (i), Bolton (1998) noted that the annual churn rate in the cellular phone industry is about $30 \%$. Therefore, Plan A's natural attrition of $24 \%$ is similar to the observed churn for existing cellular service, although this churn is usually caused by customers switching to a competitor rather than dropping the service altogether, as in our trial.

Regarding points (ii) and (iii), there are two phenomena in Figure 1 that need to be modeled. The first is usage conditional on retention, and the second is attrition. It appears that the first phenomenon is related to usage price, while the second is related to access price. 
DANAHER

Optimal Pricing of New Subscription Services

Figure 1 Relative Usage and Retention for a Market Test of a New Telecommunications Service
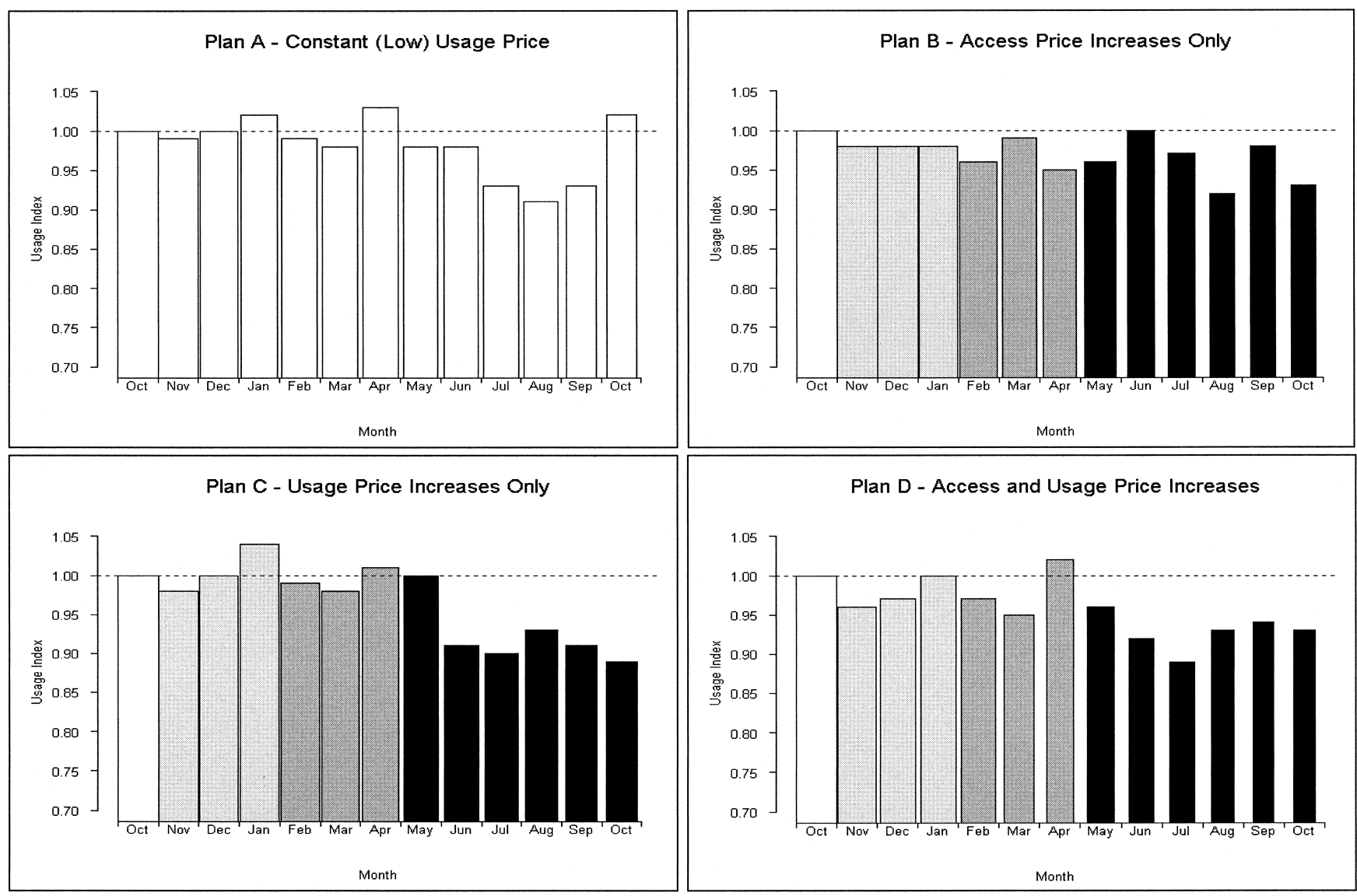

A model that ignores the retention phenomenon will clearly miss part of the key dynamics of Figure 1. What's worse, it will underestimate consumer sensitivity to access price, as we now demonstrate.

To illustrate some of the potential pitfalls, consider a model that might be fit to just the observed usage data but does not allow for trialist dropout. We show later that those who drop out tend to have lower household income, resulting in an increasing average income among those remaining in the trial. This is a censoring effect, the result of which is that average usage among those remaining in the trial could be about constant because those who remain can still afford to maintain their current usage level despite price increases. This gives the appearance of customer insensitivity to usage price increases. Some evidence of this is apparent in Figure 1 for Plan C, where usage levels do not drop noticeably for the first two price increases ( $\$ 0.05$ and $\$ 0.20 /$ minute usage price increases, respectively). Hence, naively modeling just the observed usage data and not accounting for attrition is likely to underestimate usage price elasticity and will certainly underestimate access price elasticity.

Given this caveat of modeling just usage conditional on nondropout, we develop a theoretical model of usage, which explicitly incorporates attrition by extending a model introduced by Hausman and Wise (1979). Their model is a time-series regression model, which incorporates attrition effects. Attrition is modeled as a function of usage plus other factors that might affect attrition. We make two key extensions of the Hausman and Wise (1979) model. The first is to generalize it from two to many time periods and the second is to allow for respondent heterogeneity by incorporating latent classes. 
Despite the prevalence of panels in marketing research, there has been surprisingly little research on the effects of panel attrition in the marketing literature. A notable exception is the study by Winer (1983), which used a simpler version of the Hausman and Wise (1979) method (one developed by Heckman 1976 and Olsen 1980) to correct for attrition bias. Winer's application was to a panel of people who were contacted four times and asked about their car purchasing intentions and attitudes. By the end of the fourth wave, $43 \%$ of the original panelists had dropped out of the study. More recent research efforts on attrition bias have come from the econometrics literature, such as the articles by Ridder (1990) and Verbeek and Nijman (1996). Both studies examined a generalized attrition mechanism whereby a panelist may not respond for one particular survey wave but may return in the next wave. Their models are more general than required in our case because once a panelist drops out of our experiment, he or she cannot return.

It is important to note that even though we model new services, we are not trying to model adoption, or the effect of price on adoption. A reader interested in pursuing this area is referred to Bass et al. (1994) and Jain and Rao (1990). Our primary area of investigation is the effect of price on usage and retention, given that the product has already been adopted.

\section{Modeling Approach}

In developing a model for usage and attrition of subscription services, two objectives must be satisfied:

(i) The model must fit the data from the longitudinal experiment, i.e., it should handle usage and attrition when prices increase.

(ii) The model must be flexible enough to describe a subscription service market that is closer to reality than observed in the experiment. For instance, in a real market, prices are unlikely to increase every three months, and customers that relinquish the service are likely to be replaced by new customers.

\subsection{Usage Component}

We follow the model construction derived by Hausman and Wise (1979), except that we generalize from two to many time periods ${ }^{3}$ and later introduce latent classes. Using linear regression, we relate a number of independent variables to cell phone airtime usage. The Hausman and Wise (1979) model takes the form of

$$
\begin{aligned}
y_{i t}=X_{i t} \beta+\epsilon_{i t}, \quad i & =1,2, \ldots, n, \\
t & =1,2, \ldots, T,
\end{aligned}
$$

for individual $i$ at time $t$. Notice that the independent variables in $X_{i t}$ are permitted to change with time. Because we are dealing with panel data the same individuals are being monitored over time, we could reasonably expect the error term $\epsilon_{i t}$ to have an individual component, denoted $\mu_{i}$, and an uncorrelated time effect $\eta_{i t}$, both being i.i.d. Hence, the error term in Equation (1) has the properties that

$$
\begin{array}{rlrl}
\epsilon_{i t} & =\mu_{i}=\eta_{i t}, & E\left[\epsilon_{i t}\right] & =0, \\
\operatorname{var}\left(\epsilon_{i t}\right) & =\sigma_{\mu}^{2}+\sigma_{\eta}^{2}=\sigma^{2} \quad \text { and } \quad \epsilon_{i t} \sim N\left(0, \sigma^{2}\right) .
\end{array}
$$

In addition, because we have several observations on the same person, we would expect reasonably large serial correlation across time periods. Indeed, the first-order autocorrelation for our data is 0.8 . We denote this serial correlation coefficient as $\rho$, in which case the covariance between error terms at times $t$ and $s$ is given by

$$
\operatorname{Cov}\left(\epsilon_{i t}, \epsilon_{i s}\right)=\rho^{|t-s|} \sigma^{2}, \quad t \neq s .
$$

\subsection{Attrition Component}

A panelist may drop out of the experiment at any time and not return (Ridder 1990 and Verbeek and Nijman 1996 consider the more general case where panelists are permitted to return). When attrition occurs at time $t$, we do not observe $y_{i t}$. In many situations, the occurrence of attrition depends on $y_{i t}$ in which case a regression model based on Equation (1) but with only observed data will lead to a biased estimate of $\beta$ (Hausman and Wise 1979, Winer 1983). For example, in our application, subscribers with declining usage might consider that it is no longer worthwhile continuing with their subscription.

${ }^{3}$ Winer's (1983) study had four waves, but he used the two-wave Heckman (1976) method by considering just successive pairs of waves rather than generalizing the Hausman and Wise (1979), as we do. 
Figure 2 Average Usage Among Only Those Who Drop Out of the Experiment-Indexed Against Each Person's First Month of Usage

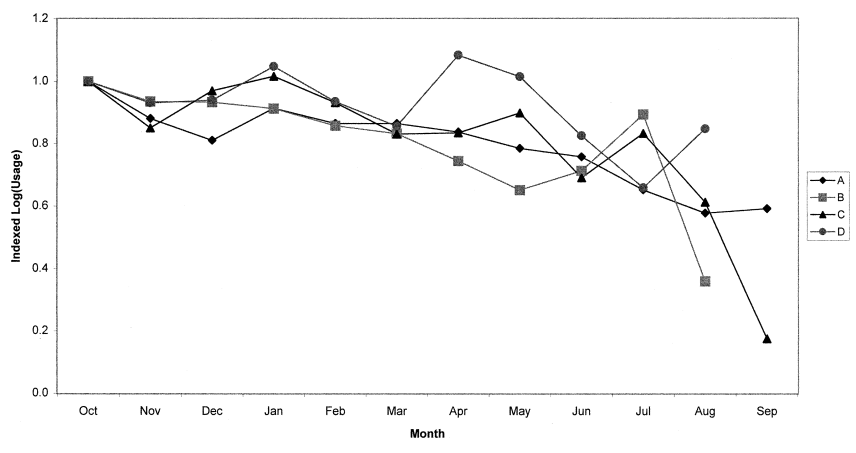

Therefore, a sign of impending attrition could be decreasing usage over time. Figure 2 illustrates this phenomenon for the subjects in our trial. Here, the average usage of just the 99 subjects who dropped out of the trial is examined. To account for individual heterogeneity in usage, each person is indexed against his or her first month's usage. The log transform of the usage data (in minutes used per month) has been taken because some people have extremely high usage. Figure 2 shows that for all four price treatments, those who drop out have an approximately linear decline in usage over time. ${ }^{4}$ To incorporate attrition effects that depend on usage, we follow the approach taken by Hausman and Wise (1979) and Winer (1983) and define an indicator variable $a_{i t}$, being 1 if person $i$ remains in the trial at time $t$ and 0 if the person drops out. Now define $y_{i t}$ to be observed if

$$
A_{i t}=\alpha y_{i t}+X_{i t} \theta+W_{i t} \gamma+\omega_{i t} \geq 0,
$$

where $W_{i t}$ is a matrix containing variables that do not affect $y_{i t}$ but do influence the probability of observing $y_{i t}$. Substituting for $y_{i t}$ in Equation (2) gives

$$
\begin{aligned}
A_{i t} & =\alpha\left(X_{i t} \beta+\epsilon_{i t}\right)+X_{i t} \theta+W_{i t} \gamma+\omega_{i t} \\
& =R_{i t} \delta+\tau_{i t \prime}
\end{aligned}
$$

where $R_{i t}=\left(X_{i t}, W_{i t}\right), \delta=(\alpha \beta+\theta, \gamma)^{\prime}$, and $\tau_{i t}=\alpha \epsilon_{i t}$ $+\omega_{i t}$. Assuming that $\omega_{i t}$ is normally distributed with mean 0 and variance $\sigma_{\omega}^{2}$, we have $\tau_{i t} \sim N\left(0, \sigma_{\tau}^{2}\right)$. As

${ }^{4}$ The steadiness of the linear decline stops in August, mainly because only a handful of subjects drop out in the last two months, which increases the variability of the average log (usage). was done by Hausman and Wise (1979) we normalize the variance of $\tau_{i t}$ by setting it to 1 , so that we now have models for the retention and attrition probabilities given by the probit model as

$$
\begin{aligned}
& \operatorname{Pr}\left(a_{i t}=1\right)=\operatorname{Pr}\left(R_{i t} \delta+\tau_{i t} \geq 0\right)=\Phi\left(R_{i t} \delta\right) \quad \text { and } \\
& \operatorname{Pr}\left(a_{i t}=0\right)=1-\Phi\left(R_{i t} \delta\right),
\end{aligned}
$$

where $\Phi(\cdot)$ is the standard normal distribution function.

To allow for the possible correlation between usage and retention (nonattrition) we define $\rho_{a}=\operatorname{corr}\left(\epsilon_{i t}, \tau_{i t}\right)$. This correlation is a measure of the strength of the relationship between usage and retention, with a positive value of $\rho_{a}$ indicating that customers with high usage have a higher probability of retention (nonattrition), while those with low usage have a lower probability of retention (i.e., higher attrition propensity). Because of the serial correlation of the $\epsilon_{i t} \mathrm{~s}$, the correlation between $\epsilon_{i t}$ and $\tau_{i s}$ is $\operatorname{corr}\left(\epsilon_{i t}, t_{i s}\right)=\rho^{|t-s|} \rho_{a}$.

Hausman and Wise (1979) show that

$$
E\left[y_{i t} \mid X_{i t}, a_{i t}=1\right]=X_{i t} \beta+\rho_{a} \sigma \frac{\phi\left(R_{i t} \delta\right)}{\Phi\left(R_{i t} \delta\right)^{\prime}}
$$

where $\phi(\cdot)$ is the standard normal density. Hence, if $\rho_{a} \neq 0$ (i.e., attrition bias is present), then a linear model relating $y_{i t}$ and $X_{i t}$, which includes just those observations remaining at time $t$, is biased. In the case of just two time periods, Heckman (1976) and Winer (1983) show that a simple adjustment can be made to the linear model, whereby $\delta$ is firstly estimated and then $\phi\left(R_{i t} \hat{\delta}\right) / \Phi\left(R_{i i} \hat{\delta}\right)$ becomes a new independent variable in Equation (1). A similar adjustment is also possible for $\mathrm{T}>2$ periods, but it requires two additional regressors, both of which must be obtained by numerical integration. Because of this computational difficulty, we instead generalize Hausman and Wise's (1979) two-period model to any number of periods by extending the likelihood approach adopted originally by Hausman and Wise (1979) but outlined in more detail by Ridder (1990). Details of this extension are given in Appendix 1.

\subsection{Overall Log-Likelihood}

Let $d_{i}$ be the period in which person $i$ drops out of the experiment. If a person completes the experiment, 
we follow the convention of Diggle and Kenward (1994) and set $d_{i}=T+1$. By substituting the respective likelihoods for dropouts and completers from Equations (A4a) and (A4b) in Appendix 1 into Equation (A3) and grouping together terms, we derive the log-likelihood as

$$
\begin{aligned}
L L= & \sum_{i=1}^{n} \sum_{t=2}^{T-1} \mathrm{I}_{\left\{d_{i}=t\right\}} \log \left[\operatorname{Pr}\left(a_{i t}=0 \mid y_{i t-1}\right)\right] \\
& +\sum_{i=1}^{n} \sum_{t=2}^{T} \mathrm{I}_{\left\{d_{i} \geq t+1\right\}} \log \left[\operatorname{Pr}\left(a_{i t}=1 \mid y_{i t}\right)\right] \\
& +\sum_{i=1}^{n} \sum_{t=2}^{T} \mathrm{I}_{\left\{d_{i} \geq t+1\right\}} \log \left[f\left(y_{i t} \mid y_{i t-1}\right)\right] \\
& +\sum_{i=1}^{n} \log \left[f\left(y_{i 1}\right)\right] .
\end{aligned}
$$

Appendix 2 gives the probabilities and densities required for the complete calculation of the log-likelihood in Equation (5). Substituting these into Equation (5) gives the exact log-likelihood function as

$$
\begin{aligned}
L L=\sum_{i=1}^{n}\{ & \sum_{t=2}^{T-1} \mathrm{I}_{\left\{d_{i}=t\right\}} \log \left[1-\Phi\left(Z_{1 i t}\right)\right] \\
& +\sum_{t=2}^{T} \mathrm{I}_{\left\{d_{i} \geq t+1\right\}} \log \left[\Phi\left(Z_{2 i t}\right)\right]-\frac{1}{2} \sum_{t=2}^{T} \mathrm{I}_{\left\{d_{i} \geq t+1\right\}} Z_{3 i t}^{2} \\
& -\frac{1}{2} Z_{4 i}^{2}-\frac{1}{2} \log \left[2 \pi \sigma^{2}\right] \\
& \left.\quad-\frac{1}{2} \log \left[2 \pi \sigma^{2}\left(1-\rho^{2}\right)\right] \sum_{t=2}^{T} \mathrm{I}_{\left\{d_{i} \geq t+1\right\}}\right\} \\
=\sum_{i=1}^{n} L L_{i} &
\end{aligned}
$$

where $Z_{1 i t}, Z_{2 i t}, Z_{3 i t}, Z_{4 i}$ are defined in Appendix 2 .

\subsection{Latent Class Model}

One of the possible problems with our proposed model is that usage levels are likely to vary by different panelist characteristics, some of which may be unobserved. A simple and robust method for handling this type of heterogeneity is to create latent panelist segments, as employed by Kamakura and Russell (1989) for consumer choice of packaged goods. ${ }^{5}$ Denote $\pi_{l}$ as the proportion of the population falling into segment $l, \sum_{i=1}^{L} \pi_{l}=1,0 \leq \pi_{l} \leq 1$. Analogously to Kamakura and Russell (1989), for the multinomial logit model, in our application we employ a separate usage/attrition model for each latent segment. The overall model is a weighted average of these segment-level models. Similarly to Kamakura and Russell (1989), we parameterize the $\pi_{l}$ proportions as $e^{\lambda_{l}} / \Sigma_{l^{\prime}=1}^{L} e^{\lambda_{l^{\prime}}}$, with $\lambda_{L}=0$ to ensure identifiability. The likelihood for the latent class generalization of the model in Equation (6) is

$$
L L_{L C}=\sum_{l=1}^{n} \log \left[\sum_{l=1}^{L} \frac{e^{\lambda_{l}}}{1+\sum_{l^{*}=1}^{L-1} e^{\lambda_{l^{*}}}} \exp \left(L L_{i l}\right)\right],
$$

where $L L_{L C}$ denotes the log-likelihood for the latent class model and $L L_{i l}$ is the log-likelihood component for the $i$ th person obtained from Equation (6) but with parameters $\left(\beta, \delta, \sigma, \rho, \rho_{a}\right)$ now indexed by $l$, corresponding to their appropriate latent class. Individual-level segment membership probabilities are given by $\pi_{i l}=e^{\lambda_{l}+L L_{i l}} / \sum_{l^{*}=1}^{L} e^{\lambda_{l^{*}}+L L_{i^{*}}}$.

\section{Application of the Model}

\subsection{Data}

The usage data for this experiment come from a product trial conducted from October 1994 to October 1995 (13 months) for a new telecommunications service. For proprietary reasons, we cannot disclose the market or the service. However, we can say that it is a type of cellular phone with service features that combine the benefits of a fixed-line phone and a cellular phone. The purpose of the trial was to ascertain the revenue-maximizing price- $\mathrm{a}$ combination of a monthly access fee and a unit price per minute of usage. Usage prices were further divided into peak and off-peak time zones, but we consider just the peak time zone in this study. An additional objective

${ }^{5}$ Of course, there are other methods that allow for heterogeneity (see, for example, Kalyanam and Putler 1997), but we found that the Kamakura and Russell model (1989) worked extremely well in our application. 
DANAHER

Optimal Pricing of New Subscription Services

Table 1 Price Levels for Each of the Treatment Groups in the Trial

\begin{tabular}{|c|c|c|c|c|c|c|c|c|}
\hline Treatment Group & \multicolumn{2}{|c|}{ A } & \multicolumn{2}{|c|}{ B } & \multicolumn{2}{|c|}{ C } & \multicolumn{2}{|c|}{$D$} \\
\hline \multicolumn{9}{|l|}{ Original no. in } \\
\hline group & \multicolumn{2}{|c|}{80} & \multicolumn{2}{|c|}{71} & \multicolumn{2}{|c|}{75} & \multicolumn{2}{|c|}{70} \\
\hline Total dropouts & \multicolumn{2}{|c|}{19} & \multicolumn{2}{|c|}{29} & \multicolumn{2}{|c|}{19} & \multicolumn{2}{|c|}{32} \\
\hline$\%$ Dropout across & \multirow{2}{*}{\multicolumn{2}{|c|}{23.8}} & & & & & & \\
\hline whole experiment & & & \multicolumn{2}{|c|}{40.8} & \multicolumn{2}{|c|}{25.3} & \multicolumn{2}{|c|}{45.7} \\
\hline & Access & Usage & Access & Usage & Access & Usage & Access & Usage \\
\hline Prices Over Time & \$/month & $\$ / \min$ & \$/month & $\$ / \min$ & \$/month & $\$ / \min$ & \$/month & $\$ / \min$ \\
\hline Oct. '94 & 0 & 0.1 & 10 & 0.1 & 0 & 0.1 & 10 & 0.1 \\
\hline Nov. '94-Jan. '95 & 0 & 0.1 & 15 & 0.1 & 0 & 0.15 & 15 & 0.15 \\
\hline Feb. '95-Apr. '95 & 0 & 0.1 & 25 & 0.1 & 0 & 0.3 & 25 & 0.3 \\
\hline May '95-0ct. '95 & 0 & 0.1 & 35 & 0.1 & 0 & 0.6 & 35 & 0.6 \\
\hline
\end{tabular}

Table 2 Descriptive Statistics for Usage-for the First Month Only

\begin{tabular}{|c|c|c|c|c|c|c|c|c|}
\hline \multirow[b]{2}{*}{$\begin{array}{l}\text { Treatment } \\
\text { Group }\end{array}$} & \multicolumn{2}{|c|}{ A } & \multicolumn{2}{|c|}{ B } & \multicolumn{2}{|c|}{ C } & \multicolumn{2}{|c|}{$D$} \\
\hline & $\begin{array}{c}\text { Min/ } \\
\text { Month }\end{array}$ & $\begin{array}{l}\text { Log of } \\
\text { Min/ } \\
\text { Month }\end{array}$ & $\begin{array}{c}\text { Min/ } \\
\text { Month }\end{array}$ & $\begin{array}{l}\text { Log of } \\
\text { Min/ } \\
\text { Month }\end{array}$ & $\begin{array}{c}\text { Min/ } \\
\text { Month }\end{array}$ & $\begin{array}{c}\log \text { of } \\
\text { Min/ } \\
\text { Month }\end{array}$ & $\begin{array}{c}\text { Min/ } \\
\text { Month }\end{array}$ & $\begin{array}{c}\log \text { of } \\
\text { Min/ } \\
\text { Month }\end{array}$ \\
\hline Mean & 249 & 4.91 & 400 & 5.25 & 310 & 5.04 & 268 & 4.99 \\
\hline Standard deviation & 272 & 1.27 & 476 & 1.47 & 339 & 1.54 & 234 & 1.41 \\
\hline Median & 181 & 5.20 & 207 & 5.33 & 210 & 5.35 & 207 & 5.33 \\
\hline Interquartile range & 279 & 1.63 & 479 & 1.89 & 319 & 1.50 & 327 & 1.69 \\
\hline
\end{tabular}

was to determine customer price sensitivity to the product.

Some 296 residential phone customers were recruited to the trial via a simple random sample. All those recruited had a fixed-line phone service, but very few had an existing cellular phone. The trialists were divided into four treatment groups of approximately equal size. The first group, labeled A, was the control group. They had no monthly access charge and only a $10 \phi /$ minute usage charge for the duration of the trial. Group B had just access price increases, while Group $C$ had only periodic usage price increases. Last, Group D, had both access and usage price increases during the trial. Table 1 gives full pricing details for each group. Trialists paid their monthly bills, as with any phone service, but were permitted to drop out of the trial at any time, without any obligations except to pay their final bill.
Table 1 shows that the highest dropout rates occur for the two groups with access price increases (B and D). The information recorded on each trialist was the number of airtime minutes used each month, their dropout month (if they dropped out), and the demographic variables of household income, whether they worked from home, were in full-time employment, and had a computer in the home. ${ }^{6}$

\subsection{Model Variables}

4.2.1. Usage-Dependent Variable. Table 2 gives some descriptive statistics for the usage data, both in raw minutes and $\log$ (minutes) per month, for just the first month of the trial (i.e., before price increases start

${ }^{6} \mathrm{~A}$ series of one-way ANOVAs conducted for each demographic variable showed that the treatment groups were not significantly different with respect to all of the demographic variables. 
to take effect on usage). One of the first things to notice is that the mean always exceeds the median, sometimes by a substantial amount (see treatment B, for instance). This is a clear sign of skewness in the data. Moreover, the mean, standard deviation, and interquartile range are similar for each group, which is a feature of the exponential distribution. Mosteller and Tukey (1977) recommend a log transformation in such instances. The log transformation has an additional advantage of "reining in" some extremely high-usage observations. Having applied the log transformation, Table 2 shows the means and medians of the logged data to be about the same. Histograms of the logged data for each group exhibit normally distributed data. Hence, from now on we use just the log-transformed usage data.

4.2.2. Usage-Independent Variables. In addition to the independent variables of access price, usage price, and the four demographic variables mentioned earlier, we also consider covariates arising from seasonal effects. Figure 1 shows the usage levels for Group A, who experience no price changes, yet their usage levels drop considerably in July and August, only to rise again in September and October. Because July and August are traditional vacation months, a drop in residential usage at this time is not surprising. Therefore, we incorporate dummy variables for three of the year's four quarters. Hence, our usage model is ${ }^{7}$

$$
\begin{aligned}
y_{i t}^{*}= & \beta_{0}+\beta_{1} p_{i t}^{a}+\beta_{2} p_{i t}^{u}+\beta_{3} \text { HINCOME }_{i} \\
& +\beta_{4} \text { WORKHOME }_{i}+\beta_{5} \text { EMPLOY }_{i} \\
& +\beta_{6} \text { COMPUTER }_{i}+\beta_{7} Q_{1 t}+\beta_{8} Q_{2 t}+\beta_{9} Q_{3 t} \\
& +\epsilon_{i t},
\end{aligned}
$$

where $y_{i t}^{*}=\log \left(y_{i t}\right), p_{i t}^{a}$ and $p_{i t}^{u}$ are the access and usage prices person $i$ is charged at time $t, \operatorname{HINCOME}_{i}=1$ if

\footnotetext{
${ }^{7}$ Notice that we do not have dummy variables for each of the treatment groups. This is because treatment dummy variables are confounded with access and usage price. Notice also that we do not include a lagged-dependent variable, as might seem reasonable with such high autocorrelation and potential heterogeneity. For instance, Winer (1983) used lagged-dependent variables, but Ridder (1990) comments that the independent variables in Equation (1) for the Hausman and Wise (1979) model must be "strictly exogenous."
}

person $i$ is in a household with income $>\$ 60,000$ per year; 0 otherwise, WORKHOME $E_{i}=1$ if person $i$ works from home; 0 otherwise, EMPLOY $i=1$ if person $i$ is employed full time; 0 otherwise, $\operatorname{COMPUTER}_{i}=1$ if person $i$ has a computer in their home; 0 otherwise, $Q_{1 t}=1$ if $t=4,5,6$ (winter); 0 otherwise, $Q_{2 t}=1$ if $t$ $=7,8,9$ (spring); 0 otherwise, $Q_{3 t}=1$ if $t=10,11$, 12 (summer); 0 otherwise.

4.2.3. Attrition-Independent Variables. Equation (2) shows that, as a minimum, the attrition model must contain the same independent variables as the usage model. Indeed, Ridder (1990) states that this is a necessary condition for identifiability of the Hausman and Wise (1979) model. Some possible additional independent variables suggested by Verbeek and Nijman (1992) for the attrition model include the number of survey waves a person is included, an indicator variable showing whether or not a person completes all waves, and a lagged-attrition variable indicating whether a person participated in the previous survey wave. All of these independent variables are suited more to the situation in which a respondent can return to the study having missed a survey wave. This does not happen in our case, so we set the attrition-independent variables to be the same as those used for the usage component of our model.

\subsection{Estimation}

We used the EM algorithm to maximize the latent class likelihood given in $\$ 3.4$ (see Wedel and Kamakura 1998 for theory and application of the EM algorithm to latent class models in marketing settings). A FORTRAN program was written to execute the EM algorithm. When maximizing the $L L_{l}$ components, we used a modified Newton method with numerical second derivatives, as executed by an IMSL routine (IMSL 1997). This IMSL routine requires first derivatives, which we give in Appendix 3.

With the latent class model, we must first determine the number of segments. Bucklin and Gupta (1992) argue in favor of using the Bayesian information criterion (BIC), defined as $L L-(m / 2) \ln (N)$, where $m$ is the number of parameters and $N$ is the number of observations (3,210 in our case). The model with the highest BIC indicates the best number of seg- 
DANAHER

Optimal Pricing of New Subscription Services

Table 3 Fitted Usage and Attrition Models

\begin{tabular}{|c|c|c|c|c|}
\hline \multirow[b]{3}{*}{ Usage Model } & \multicolumn{2}{|c|}{ One Segment } & & \\
\hline & \multirow{2}{*}{$\begin{array}{l}\text { Ignoring } \\
\text { Attrition }\end{array}$} & \multirow{2}{*}{$\begin{array}{c}\text { Incorporating } \\
\text { Attrition }\end{array}$} & \multicolumn{2}{|c|}{ Two Segments } \\
\hline & & & Segment 1 & Segment 2 \\
\hline \multirow[t]{2}{*}{ Intercept } & 4.465 & 4.501 & 5.397 & 3.781 \\
\hline & $(56.7)^{*}$ & $(568.0)$ & $(551.6)$ & $(196.3)$ \\
\hline \multirow[t]{2}{*}{ Access price } & -0.002 & -0.005 & -0.001 & -0.014 \\
\hline & $(-0.9)$ & $(-19.2)$ & $(-4.4)$ & $(-20.9)$ \\
\hline \multirow[t]{2}{*}{ Usage price } & -0.654 & -1.007 & -0.659 & -1.326 \\
\hline & $(-3.6)$ & $(-75.1)$ & $(-52.1)$ & $(-34.6)$ \\
\hline \multirow[t]{2}{*}{ HINCOME (high) } & 0.244 & 0.241 & 0.215 & 0.071 \\
\hline & $(3.9)$ & $(32.8)$ & $(22.7)$ & $(4.3)$ \\
\hline \multirow[t]{2}{*}{ WORKHOME (yes) } & 0.669 & 0.638 & 0.174 & 0.494 \\
\hline & $(9.1)$ & (71.9) & $(17.4)$ & $(18.6)$ \\
\hline \multirow[t]{2}{*}{ EMPLOY (full time) } & -0.378 & 0.363 & 0.064 & 0.422 \\
\hline & $(5.7)$ & $(46.2)$ & $(6.1)$ & $(24.6)$ \\
\hline \multirow[t]{2}{*}{ COMPUTER (yes) } & 0.060 & 0.013 & -0.155 & 0.382 \\
\hline & $(0.9)$ & $(1.6)$ & $(-15.6)$ & $(19.7)$ \\
\hline \multirow[t]{2}{*}{$0_{1}$ (winter) } & -0.041 & 0.063 & 0.034 & 0.072 \\
\hline & $(-0.5)$ & $(20.0)$ & $(13.1)$ & $(6.6)$ \\
\hline \multirow[t]{2}{*}{$\mathrm{O}_{2}$ (spring) } & -0.122 & 0.093 & 0.100 & -0.011 \\
\hline & $(-1.5)$ & $(24.3)$ & $(32.6)$ & $(-0.8)$ \\
\hline \multirow[t]{2}{*}{$\mathrm{O}_{3}$ (summer) } & -0.322 & -0.083 & -0.001 & -0.316 \\
\hline & $(-3.6)$ & $(-23.4)$ & $(-0.4)$ & $(-24.4)$ \\
\hline \multicolumn{5}{|l|}{ Attrition Model } \\
\hline \multirow[t]{2}{*}{ Intercept } & - & 1.742 & 1.956 & 1.629 \\
\hline & & $(215.0)$ & $(120.4)$ & $(95.8)$ \\
\hline \multirow[t]{2}{*}{ Access price } & - & -0.016 & -0.012 & -0.019 \\
\hline & & $(-73.2)$ & $(-29.8)$ & $(-41.5)$ \\
\hline \multirow[t]{2}{*}{ Usage price } & - & -0.386 & -0.799 & -0.164 \\
\hline & & $(-23.9)$ & $(-25.3)$ & $(-4.7)$ \\
\hline \multirow[t]{2}{*}{ HINCOME (high) } & - & 0.343 & 0.326 & 0.282 \\
\hline & & $(57.1)$ & $(27.0)$ & $(22.3)$ \\
\hline \multirow[t]{2}{*}{ WORKHOME (yes) } & - & 0.778 & 0.804 & 0.665 \\
\hline & & $(57.4)$ & (35.8) & $(18.0)$ \\
\hline \multirow[t]{2}{*}{ EMPLOY (full time) } & - & 0.258 & 0.223 & 0.249 \\
\hline & & $(42.0)$ & $(17.3)$ & $(19.3)$ \\
\hline \multirow[t]{2}{*}{ COMPUTER (yes) } & - & 0.700 & 0.829 & 0.653 \\
\hline & & $(64.4)$ & $(32.7)$ & $(30.8)$ \\
\hline$Q_{1}$ (winter) & - & -0.125 & -0.315 & 0.049 \\
\hline & & $(-14.8)$ & $(-19.4)$ & $(2.7)$ \\
\hline $\mathrm{O}_{2}$ (spring) & - & -0.216 & -0.087 & -0.317 \\
\hline & & $(-25.6)$ & $(-5.0)$ & $(-18.9)$ \\
\hline $\mathrm{O}_{3}$ (summer) & - & -0.177 & -0.078 & -0.260 \\
\hline & & $(-19.9)$ & $(-4.4)$ & $(-14.2)$ \\
\hline$\sigma$ & 1.477 & 1.526 & 0.946 & 1.763 \\
\hline & $(1052.9)$ & $(750.7)$ & $(366.4)$ & (372.2) \\
\hline$\rho$ & - & 0.776 & 0.872 & 0.629 \\
\hline & & $(1249.5)$ & (1197.8) & $(313.2)$ \\
\hline
\end{tabular}


DANAHER

Optimal Pricing of New Subscription Services

Table 3 Cont'd Fitted Usage and Attrition Models

\begin{tabular}{|c|c|c|c|c|}
\hline \multirow[b]{3}{*}{ Usage Model } & \multicolumn{2}{|c|}{ One Segment } & \multirow{2}{*}{\multicolumn{2}{|c|}{ Two Segments }} \\
\hline & \multirow{2}{*}{$\begin{array}{l}\text { Ignoring } \\
\text { Attrition }\end{array}$} & \multirow{2}{*}{$\begin{array}{l}\text { Incorporating } \\
\text { Attrition }\end{array}$} & & \\
\hline & & & Segment 1 & Segment 2 \\
\hline$\rho_{a}$ & - & $\begin{array}{c}0.346 \\
(148.2)\end{array}$ & $\begin{array}{c}0.282 \\
(55.1)\end{array}$ & $\begin{array}{c}0.482 \\
(73.7)\end{array}$ \\
\hline Segment parameter & - & - & $\begin{array}{c}0.278 \\
(28.1)\end{array}$ & 0 \\
\hline Segment size (\%) & 100 & 100 & 56.8 & 43.2 \\
\hline
\end{tabular}

Note: $t$-statistic in parentheses.

ments to use. A comparison across three segments results in the following table. The two segment model has the highest BIC, so we choose two segments for the final model.

Fit of Latent Class Models

\begin{tabular}{lccc}
\hline & One Segment & Two Segments & Three Segments \\
\hline Log-likelihood & -4914.8 & -4147.5 & -4053.5 \\
$m$ & 23 & 47 & 71 \\
BIC & -5007.7 & -4337.2 & -4340.1 \\
\hline
\end{tabular}

\subsection{Description of the Segments}

Table 3 gives the parameter estimates for a simple OLS regression model, a one-segment model, and a two-segment model. The simple regression model is a naive model that ignores the effects of attrition, which is why it has no parameter estimates for attrition. If we compare this naive model with our singlesegment model that incorporates attrition, then some interesting differences emerge. First, note the relative size of the access and usage price coefficients. The model that ignores attrition effects has smaller coefficients (in absolute value) than the model that incorporates attrition. Moreover, the naive model does not show access price to be significantly related to usage. A person using the naive model would significantly understate usage price sensitivity of consumers to the new product, as well as sensitivity of customer retention to access price.

The single-segment model incorporating attrition also shows an interesting contrast between the relative importance of access and usage price on attrition. The coefficient for access price in the attrition com- ponent of the model $(-0.016)$ is more than three times larger than the access price coefficient in the usage component of the model $(-0.005)$. This difference in relative importance is also borne out in the $t$-statistics (Bring 1994), with the access price $t$-statistic being 3.8 times bigger in the attrition model. This is intuitively reasonable and fits well with the earlier observation in Figure 1, which is that access price has more impact on customer attrition than usage of the service. Because access price is a fixed monthly cost irrespective of usage, when it gets too high there is a strong disincentive to retain the service. Usage price also plays its part on attrition, but to a lesser extent. Here, a customer with low or decreasing usage, which could result from increasing usage charges, might view the fixed monthly access fee as too high compared with the utility he or she gets from the product and, therefore, relinquish the product (drop out of the trial in this case). ${ }^{8}$

In the one-segment model, also notice the high value of $\rho$ at 0.776 , which indicates strong serial correlation. Moreover, the correlation between usage and retention, as measured by $\rho_{a}$, is reasonably strong and certainly statistically significant. This confirms the conjecture that high-usage customers are more likely to retain the service than low-usage customers.

${ }^{8}$ In contrast to our finding, Bolton (1998) found that the access fee had no impact on customer retention for her data in the cellular phone industry. This could be because of the small range of access fees ascribed to a customer for the duration of Bolton's study (1998). Moreover, because Bolton was observing an existing cellular phone market, it is likely that access fees are similar across suppliers, so they have little affect on retention. 
Turning attention to the two-segment model, we see that Segment 1 has a bigger intercept in the usage model compared with Segment 2 and, hence, higher usage on average. ${ }^{9}$ In addition, with regard to the usage model, Segment 1 is much less price sensitive to both access and usage price. Interestingly, while Segment 1 appears to be the high-usage group and is less price sensitive, this segment is still very access price sensitive when it comes to attrition. Furthermore, Segment 1's sensitivity to usage price for attrition is considerably higher than that for Segment 2, showing that when usage price gets too high, their usage tends to decline, making them more vulnerable to attrition as it becomes harder to justify the fixed monthly charge. By contrast, Segment 2, with its tendency toward low users, is not very sensitive to usage price when it comes to attrition because increasing usage costs will not add substantially to their total monthly bill. However, Segment 2 is extremely sensitive to access price, more so than Segment 1.

High- and low-usage segments were also found in a study of cellular phone pricing conducted by Jain et al. (1999). Their sample had a mixture of residential and business customers and revealed that high-usage customers were more sensitive to usage price than low-usage customers. We do not find this in our study. However, in the Jain et al. (1999) study, access price included free calling minutes, and the low-usage segment tended to have used the phone only up to the limit of their free minutes, which meant that they were unaffected by airtime usage costs. Our experiment had no free minutes included in the monthly access price, which would explain the difference in our findings. One finding that is consistent across both studies is that the low-usage segment is very sensitive to access price.

The four demographic variables show the expected effect: Those having higher income, working from

${ }^{9}$ We estimated each person's probability of segment membership using $\pi_{i l}$ above. If $\hat{\pi}_{i 1}>0.5$ we assigned person $i$ to Segment 1 , and Segment 2 otherwise. The average monthly usage for those assigned to Segment 1 was 375 minutes compared with 159 minutes for Segment 2. A similar profiling of segment membership by demographics showed that Segment 1 members tended to have higher income and disproportionately more worked from home and worked full time. There was no significant difference with respect to computer ownership. home, being in full-time employment, or having a computer in their home demonstrate both higher usage and less tendency to drop the service. Regarding seasonal effects, as seen in Figure 1, there is a significant decline in summer usage, but only for the lowusage segment.

Last, in Table 3, notice the very high value of the serial correlation for Segment 1 and that $\sigma$ is lower for Segment 1 compared with that for Segment 2. Hence, the usage pattern for Segment 1 is more consistent, with less variability. Also notice that $\rho_{a}$ for Segment 2 is nearly twice as big as that for Segment 1 , indicating the higher correlation between usage and retention for Segment 2.

\section{Model Fit}

We now test the predictive fit of our usage and attrition models by comparing model predictions (fitted values) with the observed data for each month of the experiment.

Usage. Fitted values of usage were obtained for Segments 1 and 2 by substituting the individual-level demographic information into the estimated models given in Table 3 . The actual access and usage prices in Table 1 were used for the monthly prices. An overall usage estimate was obtained for each person for each month by calculating the segment-level expected usage, conditional on retention, given by Equation (4). These segment-level estimates were averaged, with weights given by $\hat{\pi}_{i l}$, the estimated probability that person $i$ belongs to segment $l$.

Figure $3 \mathrm{~A}$ shows the average monthly observed and fitted log-usage values (indexed against the first month). The model fit is very good. The correlation between observed and fitted usage levels is reasonable, being 0.54 .

Attrition. As for usage, individual level actual data were substituted into the estimated attrition model in Table 3 to produce estimates of the survival probability at each month, i.e., $\operatorname{Pr}\left(a_{i t}=1\right)$. The expected number of trialists at each time period for each treatment group is the sum of the estimated retention probabilities for those in the relevant group. 


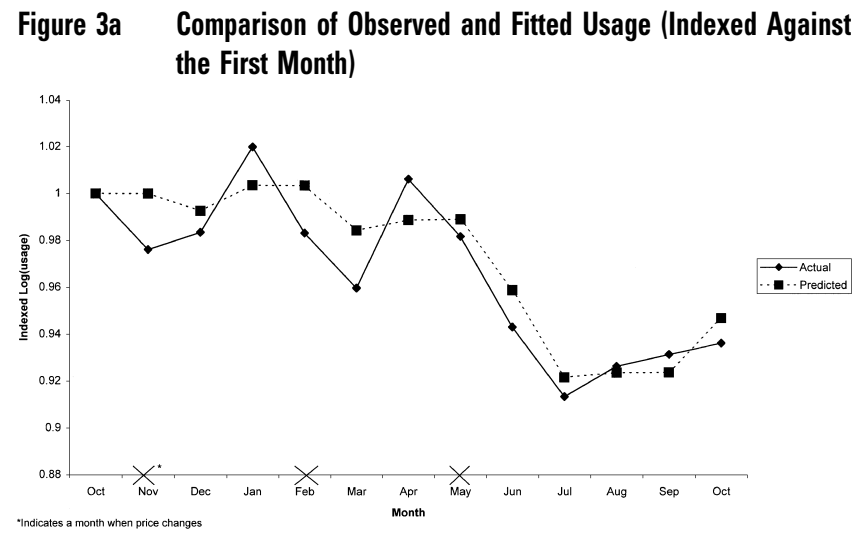

Figure 3b Comparison of Observed and Fitted Dropouts

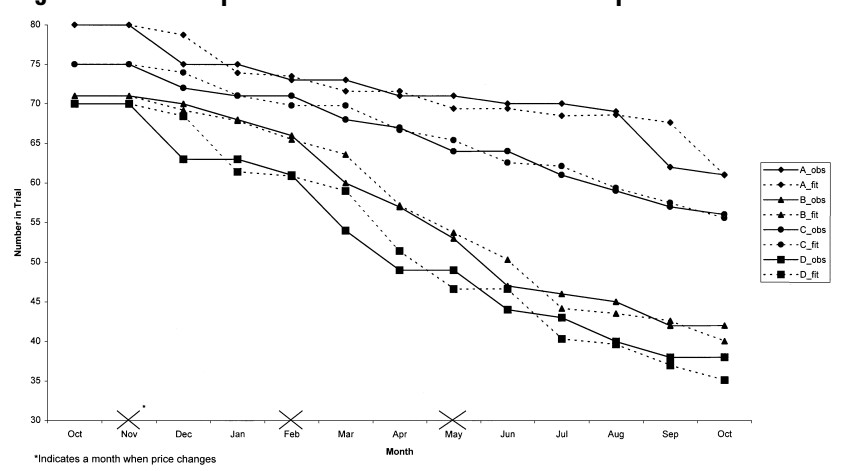

Figure 3B compares the observed and expected number of people in each treatment group over time. The fitted values are extremely close for all four treatment groups. We calculated the $\chi^{2}$ goodness-of-fit statistic across all the treatment groups for each month $(4 \times(13-1)=48$ cells $)$ and obtained a chi-squared value of 3.39. Comparing this with a $\chi^{2}$ critical value at the $5 \%$ level with 27 degrees of freedom $(48-20$ $-1=27$, where 20 is the number of estimated parameters in the latent class attrition model) of 40.1, we cannot reject the null hypothesis of a good fit.

\section{Price and Attrition Elasticities}

\subsection{Price Elasticity}

A key objective of this study is to examine customers' price sensitivity, as measured by price elasticity. In the marketing literature, Tellis (1988) reported an av- erage price elasticity of -1.8 for packaged goods, durables, and pharmaceuticals, based on a meta-analysis. Many other researchers have examined price elasticities for packaged goods (see, for example, Bolton 1989, Ehrenberg and England 1990, Raju 1992), with typical price elasticities in the range of -2 to -3 . Only a handful of studies have reported price elasticities in the telecommunications industry, and these largely appear in the economics literature. For instance, Hackl and Westlund (1996) found that price elasticities for telephone service ranged only between -0.4 and -0.9 . Rappoport and Taylor (1997) report an average elasticity of -0.44 , being much smaller than those found for Tellis' (1988) industries. Kling and Van Der Ploeg (1990) and Park et al. (1983) found usage price elasticities for just local calls ranged between -0.1 and -0.2 . While Madden et al. (1993) and Bewley and Fiebig (1988) also found telecommunications prices to be relatively inelastic, they did report that elasticities were higher for the long haul, compared with short-haul toll calls. Only the study by Madden et al. (1993) examined access and usage price simultaneously (via conjoint analysis), but access price elasticities were only given conditional on a usage price and were typically near zero. We now derive access and usage price elasticities for the telecommunications service analyzed in this experiment.

The expected usage for person $i\left(U_{i}\right)$, incorporating the effect of attrition, is obtained using Equation (4), as

$$
\begin{aligned}
U_{i} & =\sum_{l=1}^{L} \sum_{t=1}^{T} \pi_{l} \exp \left(E\left[y_{i t} \mid a_{i t}=1, X_{i t}, l\right]\right) \operatorname{Pr}\left(d_{i} \geq t \mid l\right) \\
& =\sum_{l=1}^{L} \sum_{t=1}^{T} \pi_{l} \exp \left(X_{i t} \beta_{l}+\rho_{a l} \sigma_{l} \frac{\phi\left(R_{i t} \delta_{l}\right)}{\Phi\left(R_{i t} \delta_{l}\right)}\right) \prod_{t^{*}=1}^{t} \Phi\left(R_{i t^{*}} \delta_{l}\right) .
\end{aligned}
$$

Individual-level access and usage price elasticities are, respectively, $\eta_{a}=\left(\partial U_{i} / \partial p^{a}\right)\left(p^{a} / U_{i}\right)$ and $\eta_{u}=$ $\left(\partial U_{i} / \partial p^{u}\right)\left(p^{u} / U_{i}\right)$, where the partial derivatives of $U_{i}$ with respect to access price $\left(p^{a}\right)$ and usage price $\left(p^{u}\right)$ are given in Appendix 4 (available at http://mktsci. pubs.informs.org).

Table 4 gives the average access and usage price elasticities for several levels of access and usage price using the coefficients in Table 3 for the two-segment 
DANAHER

Optimal Pricing of New Subscription Services

Table 4 Demand and Attrition Elasticities for Various Combinations of $\left(p^{a}, p^{u}\right)$

\begin{tabular}{|c|c|c|c|c|c|}
\hline \multirow[b]{3}{*}{ Price Combination } & \multicolumn{5}{|c|}{ Demand Elasticities } \\
\hline & \multicolumn{4}{|c|}{ Attrition Incorporated } & \multirow{2}{*}{$\begin{array}{l}\text { Attrition } \\
\text { Ignored } \\
(35,0.6)\end{array}$} \\
\hline & $(10,0.1)$ & $(15,0.15)$ & $(25,0.3)$ & $(35,0.6)$ & \\
\hline Access price elasticity & $\begin{array}{c}-0.06 \\
(0.003)\end{array}$ & $\begin{array}{c}-0.10 \\
(0.005)\end{array}$ & $\begin{array}{c}-0.20 \\
(0.011)\end{array}$ & $\begin{array}{c}-0.35 \\
(0.021)\end{array}$ & $\begin{array}{c}-0.07 \\
(0.007)\end{array}$ \\
\hline \multirow[t]{3}{*}{ Usage price elasticity } & $\begin{array}{c}-0.09 \\
(0.002)\end{array}$ & $\begin{array}{c}-0.14 \\
(0.005)\end{array}$ & $\begin{array}{c}-0.31 \\
(0.011)\end{array}$ & $\begin{array}{c}-0.71 \\
(0.032)\end{array}$ & $\begin{array}{c}-0.39 \\
(0.007)\end{array}$ \\
\hline & \multicolumn{5}{|c|}{ Attrition Elasticities } \\
\hline & \multicolumn{4}{|c|}{ Attrition Incorporated } & Attrition \\
\hline Price Combination & $(10,0.1)$ & $(15,0.15)$ & $(25,0.3)$ & $(35,0.6)$ & Ignored \\
\hline Access price elasticity & $\begin{array}{l}0.38 \\
(0.006)\end{array}$ & $\begin{array}{l}0.54 \\
(0.008)\end{array}$ & $\begin{array}{l}0.81 \\
(0.011)\end{array}$ & $\begin{array}{l}0.99 \\
(0.016)\end{array}$ & - \\
\hline Usage price elasticity & $\begin{array}{l}0.10 \\
(0.007)\end{array}$ & $\begin{array}{c}0.14 \\
(0.011)\end{array}$ & $\begin{array}{c}0.29 \\
(0.022)\end{array}$ & $\begin{array}{l}0.57 \\
(0.043)\end{array}$ & - \\
\hline
\end{tabular}

Note: Standard errors in parentheses, estimated by the jackknife method.

model incorporating attrition. ${ }^{10}$ In every case, usage price elasticity is considerably higher than access price elasticity, about a two-to-one ratio, showing the relative dominance of usage price over access price for determining demand.

The last two columns of Table 4 compare the elasticities for the same price combination $\left(p^{a}=\$ 35\right.$ and $\left.p^{u}=\$ 0.60\right)$, except that the last column ignores the effect of attrition on demand and estimates total expected usage with the regression coefficients in Table 3 for the OLS model that does not incorporate attrition. Contrasting these two columns shows that by ignoring the effects of attrition, access price has a much smaller effect on demand (one-fifth). Ignoring attrition also has a big effect on usage price elasticity, which is evident from the near-halving in usage price elasticity from -0.71 to -0.39 . The lower-usage elasticity observed when attrition is ignored results from the censoring effect mentioned above, whereby normal usage levels are maintained among the product "survivors," despite price increases, and this gives the (false) impression of lower usage price sensitivity.

${ }^{10}$ Elasticities are calculated at the individual level, then averaged over all individuals, as recommended by Ben-Akiva and Lerman (1985), because the demand function is nonlinear.

\subsection{Attrition Elasticity}

In addition to demand elasticity, we also examine customer churn (defined here as customers lost) because it is an important feature of subscription services. For instance, Bolton (1998) reported that the average monthly churn rate is high in the cell phone market, at $2.7 \%$ per month. High churn rates are also observed in the satellite pay TV market. To see the effects of churn, we calculated the average percent of customers who drop out each month at some time over a 13-month period for the previously used levels of access and usage prices. The lower half of Table 4 gives the attrition elasticities. It shows both access and usage attrition elasticities increasing as access and usage prices increase. However, the elasticity for usage price is considerably smaller than that for access price, as would be expected, because Table 3 shows that usage price has less influence on attrition for both segments.

As a point of comparison, Bolton (1998) reported that the churn rate was $2.7 \%$ for another cellular phone service that had an average monthly access fee of $\$ 28.35$ / month and average usage rate of $\$ 0.26 / \mathrm{min}$. The estimated churn rate for this price combination using our model is 3.1\%, being very close to Bolton's (1998) figure. 
The slightly higher churn rate in our case is probably because relinquishing the telecommunications service is easier for the panelists in our experiment, compared with the effort required to switch suppliers, as would be required in Bolton's case (1998).

\section{Optimal Pricing}

Until now, our usage and attrition models have been used to model just the observed experimental results and to obtain elasticities. As noted at the beginning of the modeling section, one of the purposes of the experiment is to determine an optimal pricing strategy for access and usage price. To achieve this, our combined usage/attrition model can estimate a revenue profile for each person over time. By summing up each person's expected revenue, we obtain the expected total revenue. Unlike the experiment, we do not vary price over time but set it to be constant over a 13-month period, which is more like the market conditions a customer will experience.

The expected total revenue is given by

\section{REVTOT}

$$
\begin{aligned}
= & \sum_{l=1}^{L} \sum_{i=1}^{n} \sum_{t=1}^{T} \pi_{l}\left\{p^{a}+p^{u} \exp \left(X_{i t} \beta_{l}+\rho_{a l} \sigma_{l} \frac{\phi\left(R_{i t} \delta_{l}\right)}{\Phi\left(R_{i t} \delta_{l}\right)}\right)\right\} \\
& \times \prod_{t^{*}=1}^{t} \Phi\left(R_{i t^{*}} \delta_{l}\right) \\
= & p^{a} \sum_{l=1}^{L} \sum_{i=1}^{n} \sum_{t=1}^{T} \pi_{l} \prod_{t^{*}=1}^{t} \Phi\left(R_{i t^{*}} \delta_{l}\right)+p^{u} U,
\end{aligned}
$$

where $U=\sum_{i=1}^{n} U_{i}$. As for usage, a consistent estimate of Equation (7) is obtained by substituting in the parameter estimates for the two-segment model in Table 3.

Figure $4 \mathrm{~A}$ shows the revenue surface as a function of access and usage price, indexed against the total revenue for $\left(p^{a}, p^{u}\right)=(\$ 0, \$ 0.05)$. The maximum revenue can be obtained directly using the partial derivatives of Equation (7), which are given in Appendix 5 (available at http://mktsci.pubs.informs.org). In Figure 4A, revenue is maximized at $(\$ 29.1, \$ 0.81)$, being a moderate monthly fee and a high-usage price. One problem with using Equation (7) for revenue
Figure 4a Revenue Surface as a Function of Access and Usage PriceNo Acquisition Cost Deducted.

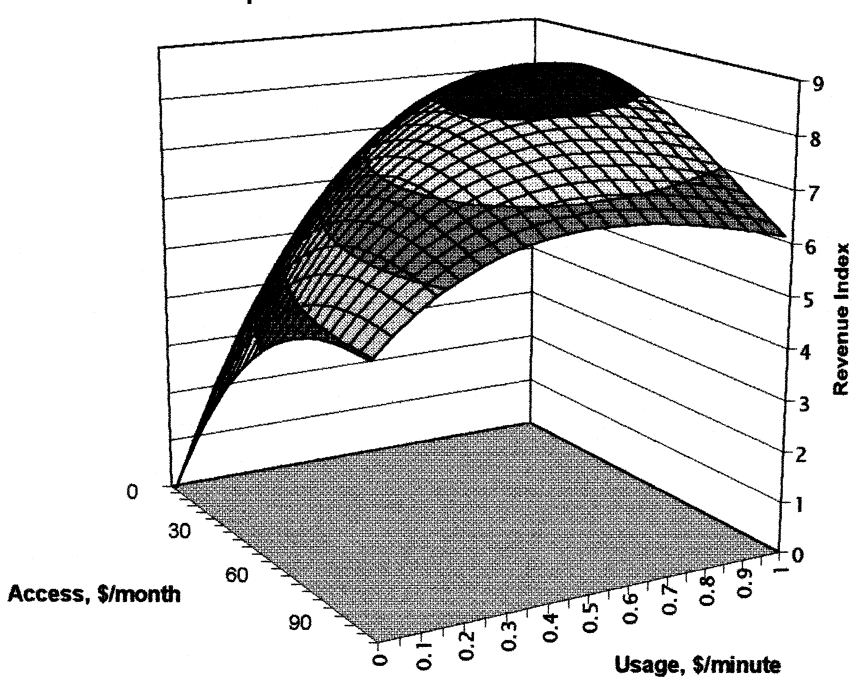

Note: $\operatorname{Max}$ at $\left(p^{a}, p^{u}\right)=(29.1,0.81)$.

maximization is that it ignores the cost of customer acquisition. In our experiment, when a panelist relinquished the service, he or she was not replaced. However, in a true market setting, it would be expected that customers who drop the service are replaced by new customers, captured by advertising or some other form of sign-up promotion. Therefore, our revenue model needs to incorporate some measure of customer acquisition cost. While it would be difficult to assign a precise acquisition cost to each customer, it is relatively straightforward to gauge aggregate acquisition cost via the advertising to sales ratio. That is, Equation (7) gives us total sales, and knowing the $\mathrm{ad} /$ sales ratio gives an aggregate value for advertising. If we denote the ad/sales ratio as $\gamma$, the net revenue having deducted customer acquisition costs is $(1-\gamma) R E V T O T$. It now remains to determine a realistic value of $\gamma$.

Several studies have looked exhaustively at advertising/sales ratios (Balasubramanian and Kumar 1990, 1997; Farris and Buzzell 1979; Paton and Conant 2000), usually with a view to finding factors related to $\gamma$. Paton and Conant (2000) observed somewhat wide variation in $\gamma$ across 844 firms in the United Kingdom. Their average ad/sales ratio was $2.03 \%$ but in particular was $2.33 \%$ for the telecommunications 
Figure 4b Revenue Surface as a Function of Access and Usage PriceAcquisition Cost Set at 2.33\% of Sales Deducted.

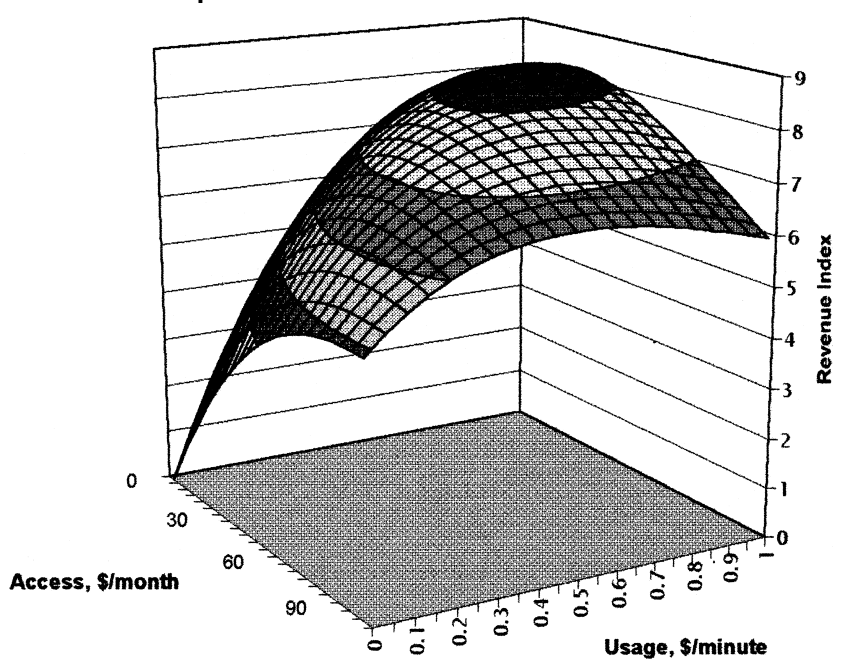

Note: $\operatorname{Max}$ at $\left(p^{a}, p^{u}\right)=(27.7,0.81)$.

industry. Hence, we initially use a $\gamma$ value of 0.0233 . Farris and Buzzell (1979) reported that $\gamma$ tends to be higher for firms producing new products, as in our case. Hence, also use a value of 0.05 for $\gamma$.

Figure 4B shows the net revenue surface for a $\gamma$ value of 0.0233 . The point of maximum revenue occurs at $\left(p^{a}, p^{u}\right)=(\$ 27.7, \$ 0.81) .{ }^{11}$ Hence, deducting the acquisition cost from Equation (7) places an increased penalty on losing customers, and this effect is combated by lowering the monthly access fee, which we have seen already has the biggest impact on customer retention. For a higher $\gamma$ value of 0.05 , the point of maximum revenue occurs at $(\$ 26.2, \$ 0.80)$, which further tries to correct for the loss in revenue because of customer attrition by lowering the monthly access fee.

As a matter of interest, we tried to compare our revenue-maximizing price combination with that derived from a naive model. In this case, a sensible naive model is one that ignores attrition effects and uses the coefficients from the second column of Table 3 as a usage-only model. However, such a naive model allowed the access price to be almost unlimited (up to $\$ 1,000 /$ month, for instance) because there is no

${ }^{11}$ We used the jackknife method (Efron 1982) to determine the standard errors for the access and usage revenue-maximizing prices, which were $\$ 2.71$ and $\$ 0.023$, respectively. penalty for increasing access price. Hence, only models that take attrition effects into account can reasonably be used for revenue maximization.

\section{Conclusion}

In this paper, we modeled observations from a market experiment for a new subscription-based telecommunications service. A theoretical model was derived that combined two basic phenomena of subscription services-namely, usage and retention. Each of these phenomena was modeled separately, but the usage model is conditional on survival and the retention model is conditional on usage. The two components of our model exhibit good predictive validity, giving usage and attrition estimates close to their actual values.

Two key objectives were revenue maximization with respect to access and usage price and determination of price sensitivity. Regarding these objectives the main findings are as follows:

(i) Access price has some affect on usage but a much stronger affect on retention.

(ii) Usage price has a strong effect on usage and a moderate effect on retention, in that if usage price increases so much that usage declines, then lower usage levels results in higher attrition.

(iii) Access price elasticity is about half that of usage price, with both elasticities generally being much smaller than 1, indicating relative inelasticity for this particular service.

(iv) Churn rate is much more sensitive to access than usage price (about a 3-to-1 ratio for moderate usage price).

(v) If just observed usage is examined and customer attrition is ignored, then price sensitivity is very likely to be substantially underestimated (on the order of $45 \%$ in our case).

Even though the experiment and model worked well in this application in terms of meeting the objectives, there are several limitations, which we now identify.

(i) The range of prices used in the experiment was not wide enough, especially for usage. For example, the revenue-maximizing usage price was around $\$ 0.80 /$ minute, which is higher than the highest usage price charged in the experiment. The first two usage 
price increases appear to have had little effect on usage, and future experiments should extend the usage price range up to $\$ 1.00 /$ minute, with fewer price levels set at the lower end.

(ii) The range of access and usage prices did not conform according to a full factorial design, in that both access and usage price increased simultaneously. Moreover, the price increases were confounded with time, so that seasonal effects may also be confounded with pricing effects. An alternative experimental plan could have started with high prices and reduced them over time (as often happens with a new service) or mixed up the valence of the price changes (to look for possible asymmetric price elasticities).

(iii) There may be some conditioning effect of the trialists, whereby they are reluctant to relinquish the service once they get used to it or depend on it. This "inertia" would tend to make the trialists less price sensitive than in a normal market setting, especially because there are no competitive effects present in this experiment.

(iv) The optimal price has been derived as if it were constant over time. Some additional modifications are required for dynamic pricing, particularly if competitive pressure had forced prices to become lower over time. Our model can accommodate dynamic pricing, but no competitive products were on the market at the time of the experiment.

Despite these limitations, the main findings should still be valid and future experiments can be refined to address the limitations. Regarding the model employed, our generalization of the Hausman and Wise (1979) model gave encouraging results, showing good predictive validity and producing intuitively reasonable results. The modeling of retention related to usage applies to many other products and services, for example, a credit card-where if a customer does not use it much and the annual subscription cost is quite high, then he or she may not renew a subscription. The same effect should be observed with magazines and newspapers, where decreased reading may not justify the subscription cost.

Although the model developed here has been applied to a new subscription service, it could equally be applied to an existing service, although some pro- vision will have to be made for competitors' prices, by using relative instead of absolute prices, for instance. An alternative model for customer acquisition could also be developed, rather than the one based on ad/sales ratios used above. For example, Thomas (2001) develops a model in which customer acquisition and retention are dependent.

Finally, an important finding of this study centers around the analysis of longitudinal panel data, which is also applicable to consumer or television panels. These panels also have panelist attrition, with higher dropout for low-volume buyers in the case of consumer panels or light TV viewers in the case of people meter panels. For consumer panels, it is possible that low-volume buyers are less price sensitive, in which case the remaining panelists tend to be more price sensitive. A model that fails to account for panelist attrition would then overstate price sensitivity. The theoretical model of usage and attrition developed in this application could also be applied to consumer panels simply by incorporating a model for panelist attrition, such as the probit model used here.

\section{Acknowledgments}

The author thanks the Editor, Area Editor, and reviewers for comments that improved the manuscript.

\section{Appendix 1. Extension of the Hausman and Wise (1979) Likelihood Model to T Periods}

First, we specify the joint distribution of $\left(y_{i 1}, y_{i 2}, \ldots, y_{i T}, a_{i 1}, a_{i 2}, \ldots\right.$, $a_{i T}$ ), which has density (suppressing the $i$ subscript for the moment),

$$
\begin{aligned}
f\left(y_{T}, y_{T-1}\right. & \left.\ldots, y_{1}, a_{T}, a_{T-1}, \ldots, a_{1}\right) \\
= & f\left(a_{T} \mid a_{T-1}, \ldots, a_{1}, y_{T}, \ldots, y_{1}\right) \\
& \times f\left(y_{T} \mid y_{T-1}, \ldots, y_{1}, a_{T-1}, \ldots, a_{1}\right) \\
& \times f\left(y_{T-1}, \ldots, y_{1}, a_{T-1}, \ldots, a_{1}\right) .
\end{aligned}
$$

Ridder (1990) notes that implicit in the Hausman and Wise (1979) model are the following two modeling assumptions:

$$
\begin{aligned}
f\left(a_{T} \mid a_{T-1}, \ldots, a_{1}, y_{T}, \ldots, y_{1}\right) & =f\left(a_{T} \mid y_{T}\right) \text { and } \\
f\left(y_{T} \mid y_{T-1}, \ldots, y_{1}, a_{T-1}, \ldots, a_{1}\right) & =f\left(y_{T} \mid y_{T-1}, \ldots, y_{1}\right) .
\end{aligned}
$$

Substituting the assumptions from Equation (A2) into Equation (A1) and further utilizing the first-order Markov model for $\left(y_{1}, y_{2}\right.$, $\ldots, y_{T}$ ) (which is implicit in the serial correlation structure of $\epsilon_{i t}$ ), we obtain 


$$
\begin{aligned}
f\left(y_{T}, y_{T-1}, \ldots, y_{1}, a_{T}, a_{T-1}, \ldots, a_{1}\right) \\
=f\left(y_{T}, \ldots, y_{1}\right) \prod_{t=1}^{T} f\left(a_{t} \mid y_{t}\right) \\
=f\left(y_{1}\right) \prod_{t=2}^{T} f\left(y_{t} \mid y_{t-1}\right) \prod_{t=1}^{T} f\left(a_{t} \mid y_{t}\right) .
\end{aligned}
$$

Diggle and Kenward (1994) derived a model similar to that in Equation (A3) in a clinical trial setting for measurements on animals, some of which dropped out of the experiment. Their dropout model was different from ours, however, being a logit rather than a probit model.

When $a_{t}=0, y_{t}$ is not observed, and Hausman and Wise (1979) state that $y_{t}$ must be "integrated out" of Equation (A3). Notationally, this is represented by $f\left(a_{t}=0 \mid y_{t-1}\right)$, that is, the dependency of $a_{t}$ on usage now refers to the previous time period (i.e., the most recent observation). Using this notation in Equation (A3), the likelihood function for someone who drops out of the trial at time $t$ given that they "survived" up until time $t-1$ is ${ }^{12}$

$$
\begin{aligned}
& \operatorname{Pr}\left(a_{t}=0 \mid y_{t-1}\right) \operatorname{Pr}\left(a_{t-1}=1 \mid y_{t-1}\right) \ldots, \operatorname{Pr}\left(a_{2}=1 \mid y_{2}\right) \\
& \quad \times\left\{f\left(y_{1}\right) \prod_{t^{*}=2}^{t-1} f\left(y_{t^{*}} \mid y_{t^{*}-1}\right)\right\} .
\end{aligned}
$$

For those remaining in the trial for the duration of the experiment, the likelihood is

$$
\prod_{t^{*}=2}^{T} \operatorname{Pr}\left(a_{t^{*}}=1 \mid y_{t^{*}}\right)\left\{f\left(y_{1}\right) \prod_{t^{*}=2}^{T} f\left(y_{t^{*}} \mid y_{t^{*}-1}\right)\right\} .
$$

\section{Appendix 2. Probability Components of the Overall Log-Likelihood}

Hausman and Wise (1979) note that from the error structure of the usage and attrition models, which are multivariate normal, that $\tau_{i t} \mid \epsilon_{i t-1}$ $\sim N\left(\rho \rho_{a} \epsilon_{i t-1} / \sigma, 1-\rho^{2} \rho_{a}^{2}\right)$ and $\tau_{i t} \mid \epsilon_{i t} \sim N\left(\rho_{a} \epsilon_{i t} / \sigma, 1-\rho_{a}^{2}\right)$. Using these conditional distributions Hausman and Wise (1979) obtain

$$
\begin{aligned}
\operatorname{Pr}\left(a_{i t}=0 \mid y_{i t-1}\right) & =\operatorname{Pr}\left(R_{i t} \delta+\tau_{i t} \leq 0 \mid y_{i t-1}\right)=1-\Phi\left(\frac{R_{i t} \delta+\rho \rho_{a} \epsilon_{i t-1} / \sigma}{\sqrt{1-\rho^{2} \rho_{a}^{2}}}\right) \\
& =1-\Phi\left(\frac{R_{i t} \delta+\rho \rho_{a}\left(y_{i t-1}-X_{i t-1} \beta\right) / \sigma}{\sqrt{1-\rho^{2} \rho_{a}^{2}}}\right)=1-\Phi\left(Z_{1 i t}\right),
\end{aligned}
$$

and similarly

$$
\operatorname{Pr}\left(a_{i t}=1 \mid y_{i t}\right)=\Phi\left(\frac{R_{i t} \delta+\rho_{a}\left(y_{i t}-X_{i t} \beta\right) / \sigma}{\sqrt{1-\rho_{a}^{2}}}\right)=\Phi\left(Z_{2 i t}\right) .
$$

In addition, for the third and fourth components of Equation (5) we require two densities. Noting that $y_{i t} \mid y_{i t-1} \sim N\left(X_{i t} \beta+\left(y_{i t-1}-\right.\right.$ $\left.\left.X_{i t-1} \beta\right) \rho, \sigma^{2}\left(1-\rho^{2}\right)\right)$, we have

${ }^{12}$ Note that no one drops out in the first period, so that $\operatorname{Pr}\left(a_{1}=1 \mid\right.$ $\left.y_{1}\right)=1$ for all panelists.

$$
\begin{aligned}
f\left(y_{i t} \mid y_{i t-1}\right) & =\frac{1}{\sigma \sqrt{\left(1-\rho^{2}\right)}} \phi\left(\frac{y_{i t}-\rho y_{i t-1}-\left(X_{i t}-\rho X_{i t-1}\right) \beta}{\sigma \sqrt{\left(1-\rho^{2}\right)}}\right) \\
& =\frac{1}{\sigma \sqrt{\left(1-\rho^{2}\right)}} \phi\left(Z_{3 i t}\right)
\end{aligned}
$$

while

$$
f\left(y_{i 1}\right)=\frac{1}{\sigma} \phi\left(\frac{y_{i 1}-X_{i 1} \beta}{\sigma}\right)=\frac{1}{\sigma} \phi\left(Z_{4 i}\right)
$$

\section{Appendix 3. First Derivatives of the Log- Likelihood Function}

In this appendix we give the first derivatives of the log-likelihood function given in Equation (6). The log-likelihood can be written equivalently as

$$
\begin{aligned}
L L= & \sum_{i=1}^{n} \sum_{t=2}^{T-1} \mathrm{I}_{\left\{d_{i}=t\right\}} \log \left[1-\Phi\left(Z_{1 i t}\right)\right]+\sum_{i=1}^{n} \sum_{t=2}^{T} \mathrm{I}_{\left\{d_{i} \geq t+1\right\}} \log \left[\Phi\left(Z_{2 i t}\right)\right] \\
& -\frac{1}{2} \sum_{i=1}^{n} \sum_{t=2}^{T} \mathrm{I}_{\left\{d_{i} \geq t+1\right\}} Z_{3 i t}^{2}-\frac{1}{2} \sum_{i=1}^{n} Z_{4 i}^{2}-\frac{1}{2}\left(n+n^{*}\right) \log (2 \pi) \\
& -\left(n+n^{*}\right) \log (\sigma)-\frac{n^{*}}{2} \log \left(1-\rho^{2}\right),
\end{aligned}
$$

with $Z_{1 i t}, Z_{2 i t}, Z_{3 i t}, Z_{4 i}$ as defined in Appendix 2 and $n^{*}=$ $\sum_{i=1}^{n} \sum_{t=2}^{T} I_{\left\{d_{i} \geq t+1\right\}}$. The partial derivatives are as follows:

$\frac{\partial L L}{\beta_{j}}=\sum_{i=1}^{n} \sum_{t=2}^{T-1} I_{\left\{d_{i}=t\right\}}\left[\frac{\phi\left(Z_{1 i t}\right)}{1-\Phi\left(Z_{1 i t}\right)}\right] \frac{\rho \rho_{a} X_{i j t-1}}{\sigma \sqrt{\left(1-\rho^{2} \rho_{a}^{2}\right)}}$

$$
\begin{aligned}
& -\sum_{i=1}^{n} \sum_{t=2}^{T} \mathrm{I}_{\left\{d_{i} \geq t+1\right\}} \frac{\phi\left(Z_{2 i t}\right)}{\Phi\left(Z_{2 i t}\right)} \frac{\rho_{a} X_{i j t}}{\sigma \sqrt{\left(1-\rho_{a}^{2}\right)}} \\
& +\sum_{i=1}^{n} \sum_{t=2}^{T} \mathrm{I}_{\left\{d_{i} \geq t+1\right\}} Z_{3 i t} \frac{\left(X_{i j t}-\rho X_{i j t-1}\right)}{\sigma \sqrt{\left(1-\rho^{2}\right)}}+\sum_{i=1}^{n} Z_{4 i} X_{i j 1} / \sigma, \\
\frac{\partial L L}{\delta_{j}}= & -\sum_{i=1}^{n} \sum_{t=2}^{T-1} \mathrm{I}_{\left\{d_{i}=t\right\}}\left[\frac{\phi\left(Z_{1 i t}\right)}{1-\Phi\left(Z_{1 i t}\right)}\right] \frac{R_{i j t}}{\sqrt{\left(1-\rho^{2} \rho_{a}^{2}\right)}} \\
& +\sum_{i=1}^{n} \sum_{t=2}^{T} \mathrm{I}_{\left\{d_{i} \geq t+1\right\}} \frac{\phi\left(Z_{2 i t}\right)}{\Phi\left(Z_{2 i t}\right)} \frac{R_{i j t}}{\sqrt{\left(1-\rho_{a}^{2}\right)}}, \\
\frac{\partial L L}{\sigma}= & \sum_{i=1}^{n} \sum_{t=2}^{T-1} \mathrm{I}_{\left\{d_{i}=t\right\}}\left[\frac{\phi\left(Z_{1 i t}\right)}{1-\Phi\left(Z_{1 i t}\right)}\right] \frac{\rho \rho_{a}\left(y_{i t-1}-X_{i t-1} \beta\right)}{\sigma^{2} \sqrt{\left(1-\rho^{2} \rho_{a}^{2}\right)}} \\
& -\sum_{i=1}^{n} \sum_{t=2}^{T} \mathrm{I}_{\left\{d_{i} \geq t+1\right\}} \frac{\phi\left(Z_{2 i t}\right)}{\Phi\left(Z_{2 i t}\right)} \frac{\rho_{a}\left(y_{i t-1}-X_{i t} \beta\right)}{\sigma^{2} \sqrt{\left(1-\rho_{a}^{2}\right)}}+\sum_{i=1}^{n} \sum_{t=2}^{T} \mathrm{I}_{\left\{d_{i} \geq t+1\right\}} Z_{3 i t}^{2} / \sigma \\
& +\sum_{i=1}^{n} Z_{4 i}^{2} / \sigma-\left(n+n^{*}\right) / \sigma, \\
\frac{\partial L L}{\rho}= & -\sum_{i=1}^{n} \sum_{t=2}^{T-1} \mathrm{I}_{\left\{d_{i}=t\right\}}\left[\frac{\phi\left(Z_{1 i t}\right)}{1-\Phi\left(Z_{1 i t}\right)}\right] \\
& \times\left[\frac{\left(\rho_{a} / \sigma\right)\left(y_{i t-1}-X_{i t-1} \beta\right) \sqrt{\left(1-\rho^{2} \rho_{a}^{2}\right)}+\rho Z_{1 i t} \rho_{a}^{2}}{1-\rho^{2} \rho_{a}^{2}}\right. \\
& +\sum_{i=1}^{n} \sum_{t=2}^{T} \mathrm{I}_{\left\{d_{i} \geq t+1\right\}}\left[\frac{\left(y_{i t-1}-X_{i t-1} \beta\right) \sigma Z_{3 i t} \sqrt{\left(1-\rho^{2}\right)}-Z_{3 i t}^{2} \rho \sigma^{2}}{\sigma^{2}\left(1-\rho^{2}\right)}\right] \\
& n^{*} \rho /\left(1-\rho^{2}\right),
\end{aligned}
$$




$$
\begin{aligned}
\frac{\partial L L}{\rho_{a}}= & -\sum_{i=1}^{n} \sum_{t=2}^{T-1} \mathrm{I}_{\left\{d_{i}=t\right\}}\left[\frac{\phi\left(Z_{1 i t}\right)}{1-\Phi\left(Z_{1 i t}\right)}\right] \\
& \times\left[\frac{(\rho / \sigma)\left(y_{i t-1}-X_{i t-1} \beta\right) \sqrt{\left(1-\rho^{2} \rho_{a}^{2}\right)}+\rho_{s} Z_{1 i t} \rho^{2}}{1-\rho^{2} \rho_{a}^{2}}\right] \\
& +\sum_{i=1}^{n} \sum_{t=2}^{T} I_{\left\{d_{i} \geq t+1\right\}} \frac{\phi\left(Z_{2 i t}\right)}{\Phi\left(Z_{2 i t}\right)}\left[\frac{\sqrt{\left(1-\rho_{a}^{2}\right)}\left(y_{i t}-X_{i t} \beta\right) / \sigma+\rho_{a} Z_{2 i t}}{1-\rho_{a}^{2}}\right] .
\end{aligned}
$$

\section{References}

Balasubramanian, Siva K., V. Kumar. 1990. Analyzing variations in advertising and promotional expenditures: Key correlates in consumer, industrial and service markets. J. Marketing 54 5768 .

- -1997 . Explaining variations in the advertising and promotional costs/sales ratio: A reanalysis. J. Marketing 61 85-92.

Bass, Frank M., Trichy V. Krishnan, Dipak C. Jain. 1994. Why the bass model fits without decision variables. Marketing Sci. 13 203-223.

Ben-Akiva, Moshe, Steven R. Lerman. 1985. Discrete Choice Analysis: Theory and Application to Travel Demand. MIT Press, Cambridge, MA.

Bewley, Ronald, Denzil G. Fiebig. 1988. Estimation of price elasticities for an international telephone demand model. J. Indust. Econom. 36(4) 393-409.

Bolton, Ruth N. 1989. The relationship between market characteristics and promotional price elasticities. Marketing Sci. 8 (2) 153-169.

- 1998. A dynamic model of the duration of the customer's relationship with a continuous service provider: The role of satisfaction. Marketing Sci. 17 (1) 45-65.

Bring, Johan. 1994. How to standardize regression coefficients. Amer. Statistician 48 (3) 209-213.

Brown, Kate, Richard Norgaard. 1992. Modeling the telecommunication pricing decision. Decision Sci. 23 (3) 673-686.

Bucklin, Randolph E., Sunil Gupta. 1992. Brand choice, purchase incidence and segmentation: An integrated modeling approach. J. Marketing Res. 29 201-215.

Diggle, Peter, M. G. Kenward. 1994. Informative drop-out in longitudinal data analysis. Appl. Statist. 43 (1) 49-93.

Dolan, Robert J., Hermann Simon. 1996. Power Pricing. The Free Press, New York.

Efron, Bradley. 1982. The Jackknife, the Bootstrap and Other Resampling Plans. Society for Industrial and Applied Mathematics, Philadelphia, PA.

Ehrenberg, A. S. C., L. R. England. 1990. Generalizing a pricing effect. J. Indust. Econom. 34 47-68.

Farris, Paul W., Robert D. Buzzell. 1979. Why advertising and promotional costs vary: Some cross-sectional analyses. J. Marketing 43 112-122.

Gabor, A. 1988. Pricing: Concepts and Methods for Effective Marketing, ed. 2. Gower Press, London, UK, and Cambridge University Press, Cambridge, UK.
_ Clive Granger. 1965. The pricing of new products. Sci. Bus. 3 141-150.

Gensch, Dennis. 1985. Empirically testing a disaggregate choice model for segments. J. Marketing Res. 22 462-467.

Gijsbrechts, E. 1993. Prices and pricing research in consumer marketing: Some recent developments. Internat. J. Res. Marketing 10(2) 115-151.

Hackl, Peter, Anders H. Westlund. 1996. Demand for international telecommunication: Time-varying price elasticity. J. Econometrics 70(1) 243-260.

Heckman, James. 1979. Sample selection bias as a specification error. Econometrica 47(1) 153-162.

Herriges, J. A., K. K. King. 1994. Residential demand for electricity under inverted block rates: Evidence from a controlled experiment. J. Bus. Econom. Statist. 12(4) 419-430.

IMSL. 1997. Math Library, Volumes 1 \& 2. Visual Numerics Inc., Houston, TX.

Jain, Dipak C., Ram C. Rao. 1990. Effect of price on the demand for durables: Modeling, estimation and findings. J. Bus. Econom. Statist. 8(2) 163-170.

_ Eitan Muller, Naufel J. Vilcassim. 1999. Pricing patterns of cellular phones and phone calls. Management Sci. 45(2) 131141.

Kalyanam, Kirthi, Daniel S. Putler. 1997. Incorporating demographic variables in brand choice models: An indivisible alternatives framework. Marketing Sci. 16(2) 166-181.

Kling, John P., Stephen S. Van Der Ploeg. 1990. Estimating local call elasticities with a model of stochastic class of service and usage choice. A. De Fontenay, M. H. Shugard, D. S. Sibley, eds. Telecommunications Demand Modeling: An Integrated View. NorthHolland, Amsterdam, The Netherlands, 119-136.

Kohli, R., Vijay Mahajan. 1991. A reservation price model for optimal pricing of multiattribute products in conjoint analysis. $J$. Marketing Res. 28 347-354.

Lemon, Katherine, Russell S. Winer. 1995. A model of customer retention for new-to-the world products and services. Working paper, Duke University, Durham, NC.

Madden, Gary, Harry Bloch, David Hensher. 1993. Australian telephone network subscription and calling demands: Evidence from a stated-preference experiment. Inform. Econom. Policy 5(3) 207-230.

Mahajan, Vijay, Paul E. Green, S. M. Goldberg. 1982. A conjoint model for measuring self- and cross-price/demand relationships. J. Marketing Res. 29 334-342.

Mitchell, B. M., I. Vogelsang. 1991. Telecommunications Pricing: Theory and Practice. Cambridge University Press, Cambridge, UK.

Mohn, N. C. 1995. Pricing research for decision making. Marketing Res.: Magazine Management Appl. 7(1) 10-19.

Morwitz, Vicki G., Eric Johnson, David Schmittlein. 1993. Does measuring intent change behavior. J. Consumer Res. 20 46-61.

Mosteller Frederick, John W. Tukey. 1977. Data Analysis and Regression: A Second Course in Statistics. Addison Wesley, Reading, MA. 
DANAHER

Optimal Pricing of New Subscription Services

Nagle, T. T., R. K. Holden. 1995. The Strategy and Tactics of Pricing, ed. 2. Prentice Hall, Englewood Cliffs, NJ.

Olsen, Randall J. 1980. A least squares correction for selectivity bias. Econometrica 48(7) 1815-1820.

Oren, S. S. 1984. Comments on pricing research in marketing: The state of the art. J. Bus. 57(1) S61-S64.

Park, Rolla E., Bruce M. Wetzel, Bridger M. Mitchell. 1983. Price elasticities for local telephone calls. Econometrica 51(6) 16991730.

Paton, David, Neil Conant. 2000. An introduction to the 1999 advertising and industry survey. Working paper, Nottingham University Business School, Nottingham, UK.

Puliyel, T., V. Ravi. 1990. Pricing research: A comparison of three techniques. J. Market Res. Soc. 32(2), 207-216.

Raju, J. S. 1992. The effect of price promotions on variability of product category sales. Marketing Sci. 11(3) 207-220.

Rao, Vithala R. 1984. Pricing research in marketing: The state of the art. J. Bus. 57(1) S39-S60.

Rappoport, Paul N., Lester D. Taylor. 1997. Toll price elasticities estimated from a sample of U.S. residential telephone bills. Inform. Econom. Policy 9(1) 51-70.

Ratza, C. L. 1993. A client-driven model for service pricing. J. Professional Services Marketing 8(2) 55-64.

Reichheld, Fredrick F., W. Earl Sasser. 1990. Zero defections: Quality comes to services. Harvard Bus. Rev. 68(5) 105-111.

Ridder, Geert. 1990. Attrition in multi-wave panel data. J. Hartog, G. Ridder, J. Theeuwes, eds. Panel Data and Labor Market Studies. North-Holland, Amsterdam, The Netherlands.
Rosenberg, Larry J., John A. Czepiel. 1984. A marketing approach to customer retention. J. Consumer Marketing 1 45-51.

Sheiner, Lewis B., Stuart L. Beal, Adrian Dunne. 1997. Analysis of nonrandomly censored ordered categorical longitudinal data from analgesic trials. J. Amer. Statist. Association 92(440) 12351244.

Tellis, Gerard J. 1988. The price elasticity of selective demand: A meta-analysis of econometric models of sales. J. Marketing Res. 25(4) 331-341.

Thomas, Jacquelyn S. 2001. A methodology for linking customer acquisition to customer retention. J. Marketing Res. 38(2) 262268.

Verbeek, Marno, Theo Nijman. 1992. Testing for selectivity bias in panel data models. Internat. Econom. Rev. 33 681-703.

_ _ 1996. Incomplete panels and selection bias. L. Matyas, P. Sevestre, eds. The Econometrics of Panel Data, ed. 2. Kluwer Academic, Dordrecht, The Netherlands.

Wedel, Michel, Wagner A. Kamakura. 1998. Market Segmentation: Conceptual and Methodological Foundations. Kluwer Academic, Boston, MA.

Winer, Russell S. 1986. A reference price model of brand choice for frequently purchased products. J. Market Res. 23 250-256.

- 1983. Attrition bias in econometric models estimated with panel data. J. Market Res. 20 177-186.

Wittink, Dick R., Phillip Cattin. 1989. Commercial use of conjoint analysis: An update. J. Marketing 53 91-96.

This paper was received February 8, 2001, and was with the authors 5 months for 2 revisions; processed by Pradeep Chintagunta. 